SHORT TITLE: $\quad$ Reading difficulties and child mental health

\title{
Why are reading difficulties associated with mental health problems?
}

\author{
Mark E. Boyes ${ }^{1}$, Suze Leitao ${ }^{1}$, Mary Claessen ${ }^{1}$, Nicholas A. Badcock ${ }^{2}, \&$ Mandy \\ Nayton ${ }^{1,3}$ \\ 1 \\ 1: School of Psychology and Speech Pathology, Curtin University, Perth, WA, \\ Australia. \\ 2: ARC Centre of Excellence in Cognition and its Disorders, Department of Cognitive \\ Science, Macquarie University, NSW, Australia. \\ 3: The Dyslexia-SPELD Foundation, Perth, WA, Australia \\ Acknowledgements:
}

This work was supported by the Western Australian Health Promotion Foundation (Healthway), through research grant (24342)

Word Count: $\quad 1,574$ (including abstract and references)

Corresponding Author:

Dr Mark Boyes

Research Fellow

School of Psychology and Speech Pathology

Faculty of Health Sciences, Curtin University

GPO Box U1987

Perth, Western Australia, 6845

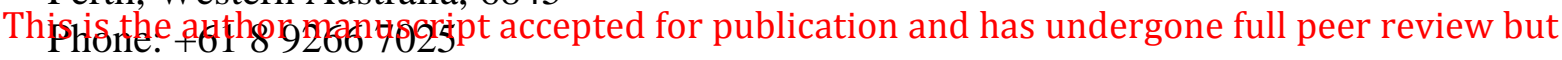

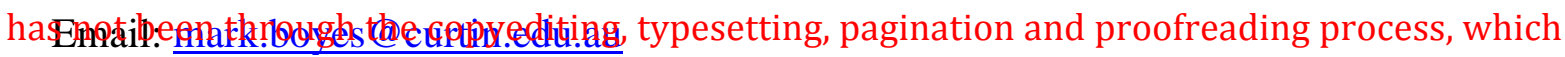

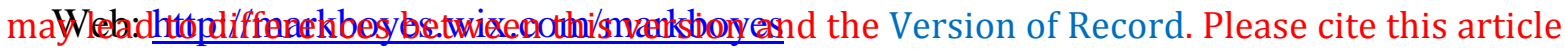
as Tdyitteri 109 medyoy

This article is protected by copyright. All rights reserved. 
Reading difficulties and child mental health 1

\begin{abstract}
A growing literature indicates children with reading difficulties are at elevated risk for mental health problems; however, little attention has been given to why this might be the case. Associations between reading difficulties and mental health differ substantially across studies, raising the possibility that these relationships may be ameliorated or exacerbated by risk or resilience-promoting factors. Using socio-ecological theory as a conceptual framework, we outline four potential lines of research that could shed light on why children with reading difficulties are at risk of mental health problems and identify potential targets for intervention.
\end{abstract}

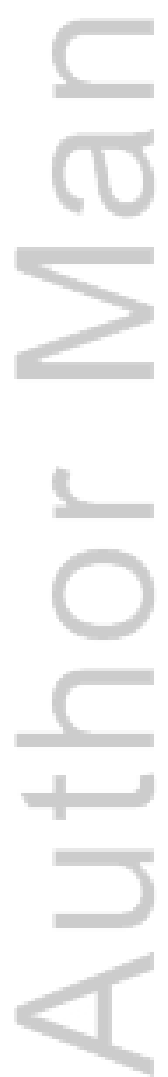

This article is protected by copyright. All rights reserved. 
A growing literature indicates that children with reading difficulties are at elevated risk for both internalising (emotional) and externalising (behavioural) problems. Longitudinal studies have demonstrated that reading difficulties are prospectively associated with later internalising (Arnold et al., 2005) and externalising (Halonen, Aunola, Ahonen, \& Nurmi, 2006; Snowling, Muter, \& Carroll, 2007) symptoms, suggesting that reading difficulties are a risk factor for the development of later mental health problems. With regard to internalising symptoms, reading difficulties have been shown to be associated with depression (Arnold et al., 2005; Eissa, 2010; Maughan \& Carroll, 2006), anxiety (Arnold et al., 2005; Carroll \& Iles, 2006; Carroll, Maughan, Goodman, \& Meltzer, 2005; Eissa, 2010; Whitehouse, Spector, \& Cherkas, 2009), somatic complaints (Arnold et al., 2005; Eissa, 2010), low mood (Carroll et al., 2005), and general socio-emotional problems (Terras, Thompson, \& Minnis, 2009). With regard to externalising symptoms, reading difficulties have been associated with behavioural problems (Maughan \& Carroll, 2006; Snowling et al., 2007; Terras et al., 2009), conduct disorder (Carroll et al., 2005; Thambirajah, 2010), and both anger and aggression (Eissa, 2010; Morgan, Farkas, \& Wu, 2012).

However, while evidence for relationships between reading difficulties and poor mental health is accumulating, little research has examined why this might be the case. If we are to design interventions to promote mental health in children with reading 
difficulties, it is essential to identify mechanisms explaining psychological outcomes for these children. The strength of associations between reading difficulties and mental health differ substantially across studies (effect sizes range between 'small' and 'large') and some studies find no associations between reading difficulties and mental health or related constructs such as self-worth (Burden, 2008; Carroll et al., 2005). This variability raises the possibility that relationships between reading difficulties and mental health may be ameliorated or exacerbated by risk or resilience-promoting factors. Socio-ecological frameworks (e.g. Bronfrenbrenner, 1979) postulate a child as being at the centre of a network of interacting influences operating at different levels (e.g. individual, family, and community), and that resources in one area may buffer against deficits in another. Identifying potential risk and resilience-promoting factors will not only inform the theoretical understanding of associations between reading difficulties and child mental health, but will also provide potential targets for intervention. Here we recommend four potential lines of research that could shed light on why children with reading difficulties are at risk of mental health problems.

\section{1) Novel research identifying risk and resilience-promoting factors associated} with mental health in children with reading difficulties

Potential risk and resilience-promoting factors could be identified through $i$ ) in-depth qualitative research with children, parents, educators, and clinicians to generate a list of factors deemed important by stakeholders, and $i$ ) identifying risk (e.g. low self-esteem, 
peer rejection, bullying, family instability) and resilience-promoting (e.g. supportive parents and teachers, coping skills, and emotion-regulation) factors associated with mental health in the broader child psychology literature. Once a candidate list of factors has been generated, longitudinal quantitative research is needed to determine if they mediate and/or moderate relationships between reading difficulties and mental health across development.

\section{2) Collaborating with clinical service providers}

Clinicians collect detailed information on clients referred for assessment and treatment. For example, the Dyslexia-SPELD Foundation (DSF) in Western Australia collects information on achievement (reading, spelling, written expression, handwriting, and mathematics) and cognitive abilities (intellectual functioning, phonological processing, attention, and executive functioning). Parent reports of behavioural and socio-emotional development are also recorded, along with information on child self-esteem, family background, prenatal and early childhood development, medical history, educational attainment, parent-child relationship, relationships with siblings, peers and teachers, motivation at school, and any remedial assistance the child has received. DSF conducts around 1,000 assessments annually, and the majority of parents give consent for data to be used for research purposes. Collaborating with clinical service providers, such as DSF, provides unique opportunities to use detailed clinical records to identify factors associated with mental health in children with reading difficulties. This may be in the form of $i$ ) secondary analysis of data already collected, or $i i)$ the generation of new data, 
for example longitudinal follow-up of previously assessed children. We firmly believe that academic-clinician collaboration will be particularly fruitful in illuminating links between reading impairment and mental health.

\section{3) Collaborating on existing trials of mental health promotion interventions}

Universal school-based mental health promotion programs focus on competence, resilience, and skill building (e.g. emotion recognition and regulation, social skills, positive thinking, and social/interpersonal skills; Roberts et al., 2010). If embedded into the curriculum, and delivered by school staff, school-based prevention and intervention programs are cost-effective and can reduce risks for later mental health problems in primary school children generally (Neil \& Christensen, 2009). However, universal mental health or prevention programs typically yield small effect sizes (Durlak, Weissberg, Dymnicki, Taylor, \& Schellinger, 2011). Given that the majority of children will not develop a mental health problem, it would be helpful to see if such programs are particularly effective for potentially vulnerable subgroups such as children with reading difficulties. If this is the case, the skills targeted by these interventions may be salient risk and resilience-promoting factors moderating and/or mediating associations between reading difficulties and mental health. This knowledge will contribute to the theoretical understanding of why reading difficulties are linked with mental health problems, and could also identify effective intervention components that may be tailored to supplement reading remediation programs. 


\section{4) Including brief measures of mental health in trials of reading interventions}

It may be the case that mental health problems arise as a direct consequence of reading difficulties. If this is the case, then remediation of reading skills should also improve child self-esteem and mental health. Many child mental health measures (such as the Strengths and Difficulties Questionnaire, Goodman, 1997) are short, easy to administer, and can be completed by children, parents, or teachers. These measures could be included as secondary outcomes in trials of interventions to remediate reading. Of particular interest would be investigating whether reading intervention improves reading/academic-related self-esteem, and whether this is linked with improvements in mental health.

Although by no means exhaustive, we believe that together these four lines of research will provide a firm foundation for systematically investigating why children with reading difficulties are at elevated risk for both emotional and behavioural problems, will identify factors that might indicate particular vulnerability, and will underpin the development of interventions promoting mental health in these children.

This article is protected by copyright. All rights reserved. 
Reading difficulties and child mental health 7

References

Arnold, E., Goldston, D., Walsh, A., Reboussin, B., Daniel, S., Hickman, E., \& Wood, F. (2005). Severity of emotional and behavioral problems among poor and typical readers. Journal of Abnormal Child Psychology, 33, 205-217.

Bronfrenbrenner, U. (1979). The ecology of human development: Experiments by nature and design. Cambridge: Harvard University Press.

Burden, R. (2008). Is dyslexia necessarily associated with negative feelings of selfworth? A review and implications for future research. Dyslexia, 14, 188-196.

This article is protected by copyright. All rights reserved. 
Carroll, J. M., \& Iles, J. E. (2006). An assessment of anxiety levels in dyslexic students in higher education. British Journal of Educational Psychology, 76, 651-662.

Carroll, J. M., Maughan, B., Goodman, R., \& Meltzer, H. (2005). Literacy difficulties and psychiatric disorders: Evidence for comorbidity. Journal of Child Psychology and Psychiatry, 46, 524-532.

Durlak, J. A., Weissberg, R. P., Dymnicki, A. B., Taylor, R. D., \& Schellinger, K. B. (2011). The impact of enhancing students' social and emotional learning: A meta-analysis of school-based universal interventions. Child Development, 82, 405-432.

Eissa, M. (2010). Behavioral and emotional problems associated with dyslexia in adolescence. Current Psychiatry, 17, 17-25.

Goodman, R. (1997). The Strengths and Difficulties Questionnaire: A research note. Journal of Child Psychology and Psychiatry, 38, 581-586.

Halonen, A., Aunola, K., Ahonen, T., \& Nurmi, J.-E. (2006). The role of learning to read in the development of problem behaviour: A cross-lagged longitudinal study. British Journal of Educational Psychology, 76, 517-534.

Maughan, B., \& Carroll, J. M. (2006). Literacy and mental disorders. Current Opinion in Psychiatry, 19, 350-355.

Morgan, P., Farkas, G., \& Wu, Q. (2012). Do poor readers feel angry, sad, and unpopular? Scientific Studies of Reading, 16, 360-381. 
Neil, A., \& Christensen, H. (2009). Efficacy and effectiveness of school-based prevention and early intervention programs for anxiety. Clinical Psychology Review, 29, 208-215.

Roberts, C., Kane, R. T., Bishop, B., Cross, D., Fenton, J., \& Hart, B. (2010). The prevention of anxiety and depression in children from disadvantaged schools.

$=$ Behaviour Research and Therapy, 48, 68-73.

Snowling, M. J., Muter, V., \& Carroll, J. M. (2007). Children at family risk of dyslexia: A follow-up in early adolescence. Journal of Child Psychology and Psychiatry, $48,609-618$.

Terras, M., Thompson, L., \& Minnis, H. (2009). Dyslexia and psycho-social functioning: An exploratory study of the role of self-esteem and understanding. Dyslexia, 15, 304-327.

Thambirajah, M. S. (2010). Developmental dyslexia: Clinical aspects. Advances in Psychiatric Treatment, 16, 380-387.

Whitehouse, A., Spector, T., \& Cherkas, L. (2009). No clear genetic influences on the association between dyslexia and anxiety in a population-based sample of female twins. Dyslexia, 15, 282-290.

This article is protected by copyright. All rights reserved. 


\section{University Library}

\section{- M M I E R R V A gateway to Melbourne's research publications}

Minerva Access is the Institutional Repository of The University of Melbourne

Author/s:

Boyes, ME;Leitao, S;Claessen, M;Badcock, NA;Nayton, M

Title:

Why Are Reading Difficulties Associated with Mental Health Problems?

Date:

2016-08-01

Citation:

Boyes, M. E., Leitao, S., Claessen, M., Badcock, N. A. \& Nayton, M. (2016). Why Are

Reading Difficulties Associated with Mental Health Problems?. DYSLEXIA, 22 (3),

pp.263-266. https://doi.org/10.1002/dys.1531.

Persistent Link:

http://hdl.handle.net/11343/291563 